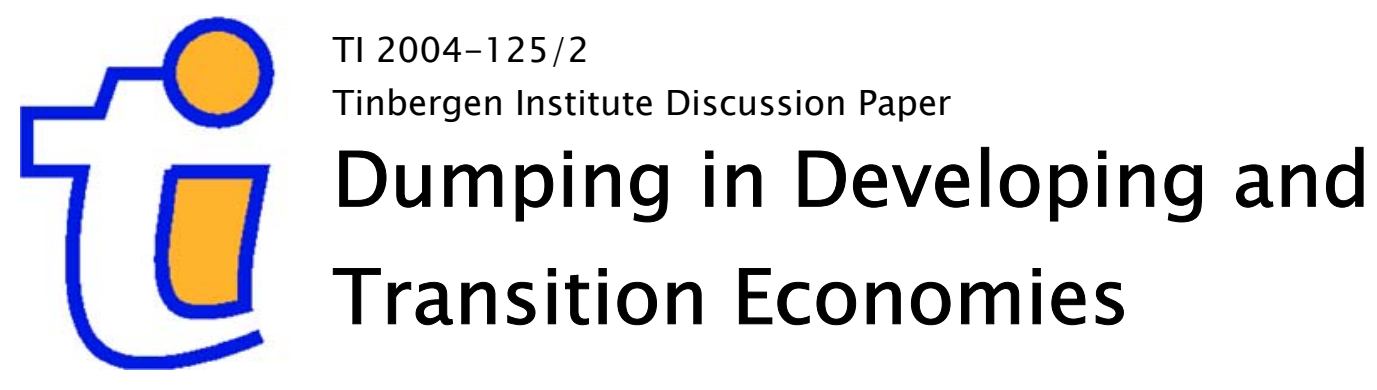

José Luis Moraga-González Jean-Marie Viaene

Faculty of Economics, Erasmus Universiteit Rotterdam, and Tinbergen Institute. 
Tinbergen Institute

The Tinbergen Institute is the institute for economic research of the Erasmus Universiteit Rotterdam, Universiteit van Amsterdam, and Vrije Universiteit Amsterdam.

Tinbergen Institute Amsterdam

Roetersstraat 31

1018 WB Amsterdam

The Netherlands

Tel.: $\quad+31(0) 205513500$

Fax: $\quad+31(0) 205513555$

Tinbergen Institute Rotterdam

Burg. Oudlaan 50

3062 PA Amsterdam

The Netherlands

Tel.: $\quad+31(0) 104088900$

Fax: $\quad+31(0) 104089031$

Please send questions and/or remarks of nonscientific nature to driessen@tinbergen.nl.

Most TI discussion papers can be downloaded at http://www.tinbergen.nl. 


\title{
Dumping in Developing and Transition Economies*
}

\author{
José Luis Moraga-González and Jean-Marie Viaene ${ }^{\dagger}$ \\ Erasmus University Rotterdam, Tinbergen Institute and CESifo
}

This version: November 16, 2004

\begin{abstract}
We build a simple theoretical model to understand why developing and transition economies have increasingly applied anti-dumping laws. To that end, we investigate the strategic incentives of oligopolistic exporting firms to undertake dumping in these economies. We show that dumping may be due to cross-country differences in income, to the extent of tariff protection and to the exchange rate depreciations observed recently. Dumping may arise even if consumers exhaust all arbitrage possibilities.
\end{abstract}

JEL classification: F12, F13, P31

Keywords: Dumping, Exchange Rate, Optimal Trade Policy, Product Quality.

*We thank Alan Deardoff, Joe Francois, Abraham Hollander, Henrik Horn, Jee-Hyeong Park, Thomas Prusa, Robert Staiger, Robert Stern, the seminar participants at the University of Montreal, at the International Workshop "Centennial of Anti-Dumping Legislation and Implementation" at the University of Michigan, and at the Meeting of the European Trade Study Group (Nottingham) for helpful comments and suggestions. This paper was written while Viaene was visiting the Department of Economics of the University of Michigan, whose hospitality and financial support are gratefully acknowledged. He also thanks the Center for European Studies of the University of Michigan and the Royal Netherlands Academy of Arts and Sciences for financial support.

${ }^{\dagger}$ Address for correspondence: Erasmus University Rotterdam, Department of Economics, Burg. Oudlaan 50, 3062 PA Rotterdam, The Netherlands. E-mails: <moraga@few.eur.nl> and < viaene@few.eur.nl> 


\section{Introduction}

Times have changed in the world of anti-dumping activities. While anti-dumping actions were only used by major industrial countries less then a decade ago, they are now the trade policy of choice of developing and transition economies as well. On a worldwide basis, India has since 2001 overtaken the US in terms of initiations of new anti-dumping cases. In terms of cases per dollar of imports, India's intensity of anti-dumping use is seven times the US figure, though this is less than Argentina's intensity, which is 20 times the US number (Finger, Ng and Wangchuk, 2000). Noting that most anti-dumping investigations against Member States of the European Community emanate from countries like China, Czech Republic, Bulgaria, India, Russia, etc., the European Community concludes: "Anti-dumping is now a global instrument and every country is now both a potential user and potential target of anti-dumping action" (EC, 2002, p.1).

A natural question that arises from these observations is what are the conditions that lead to dumping. In recent years, a number of theoretical models have been developed to examine the export behavior of firms under different market structures. The survey by Blonigen and Prusa (2003) thoroughly reviews the existing theory and empirics and describes the various market outcomes of resulting anti-dumping actions. The existing literature largely confines attention to outcomes of anti-dumping laws in developed countries. However, dumping by Western firms is also observed in industries of developing and transition economies whose economic characteristics are different. The purpose of this paper is to examine the strategic incentives of oligopolistic exporting firms to undertake dumping in poorer countries and to understand why the latter have increasingly applied anti-dumping laws. We shall focus on several important factors that influence firms' export behavior: a product quality gap, countries' differences in size and income, tariff schedules, and the exchange rate.

Though developing and transition economies differ in many respects, there are a number of common economic characteristics that have inspired our framework of analysis:

- A limited concern for quality standards has often driven firms in these economies to supply goods whose quality is inferior to that of Western firms. This is established in a number of empirical studies that show a quality advantage of imports over exports by comparing average unit values (Aturupane et al., 1999; Lankhuizen, 2000).

- There is also convincing evidence that a significant proportion of trade involves trade of vertically differentiated goods (Greenaway et al., 1994, 1995). 
- The current nominal protection rates reveal high levels of tariff protection, from two to three times those of industrial countries (see the World Bank website).

- Trends in nominal exchange rates indicate a tendency towards depreciation and show fluctuations in currencies that are often larger than the applied tariff rates. Examples include the Russian Ruble and the Argentinian Peso.

- It is common that anti-dumping cases involve just two players, a local producer and a foreign exporter. This observation derives from anti-dumping proceedings of the US and the EC. For example, petitions which are filed by US industries against imports concern products which are usually classified under 10-digit subheadings of the Harmonized Tariff Schedule of the United States. Even in a large trading nation like the US, sources of supply at this level of disaggregation concern a few firms only. See, for example, USITC (2001, 2002).

The specific model we analyse is as follows. We model bilateral international trade by considering the market for a single (quality-differentiated) product in a two-country world, home and foreign. Domestic and foreign consumers have heterogenous preferences for the sole product attribute, namely, quality. The distribution of consumer preferences is different in that foreign consumers have more sophisticated tastes. Also, as consumers may decide not to consume, market sizes at both locations are endogenous. Quality development is costly and the foreign firm is assumed to be more efficient with regard to quality development costs. In this environment, two types of quality are produced under free trade, the most efficient firm having the quality leadership. Trade takes the form of intra-industry trade in vertically differentiated goods whose determinants relate to those found traditionally in the empirical literature (see Greenaway et al., 1994, 1995). However, free trade does not lead to a social optimum (in a second-best sense) and governments in both countries have incentives to impose an optimal trade policy.

The main result of this paper is that dumping is a natural strategy of firms in the sense that it always takes place. Dumping arises as a consequence of differences in the distribution of tastes across countries engaged in trade. The foreign firm may unilaterally dump into the poorer country or vice versa; reciprocal dumping may also occur, a necessary condition being that at least one of the countries involved in trade levies a positive tariff on imports.

Another result we derive is that as free trade is not optimal, the strategic incentive to dump may be the result of tariff protection imposed by both countries in the first place. In particular, reciprocal dumping is more likely the higher the import tariffs. Moreover, as exchange rate movements affect 
firms in opposite directions, an exchange rate depreciation (appreciation) increases the likelihood of unilateral dumping in the domestic (foreign) market.

We finally explore whether dumping can still arise if consumers exhaust arbitrage possibilities via parallel trade. We find that if market conditions lead to reciprocal dumping, there is no gain to be derived from the re-shipment of goods. Under unilateral dumping, there are gains from arbitrage but if tariff rates are positive dumping by the foreign firm occurs even if all arbitrage possibilities are exhausted.

The paper is organized as follows. In section 2, we lay out the general structure and describe the international trade game. In section 3 , we derive the market equilibrium and obtain the conditions for dumping. We also outline the effects of changes in the exchange rate level on dumping. In section 4 , we discuss a game between governments which simultaneously decide whether or not to impose tariffs to maximize national welfare. Section 5 discusses the implications of arbitrage of goods on unilateral and reciprocal dumping. We conclude in section 6 . The appendix contains a glossary of symbols.

\section{The Model}

We analyze dumping in the context of markets in two countries, which we shall call domestic and foreign, the latter denoted by "*". The domestic country is meant to represent a developing or transition economy; the foreign country a developed economy. Suppose that a population of measure 1 lives at home and that preferences of domestic consumer $\theta$ are given by the quasi-linear utility function:

$$
U=\left\{\begin{array}{cc}
\theta q-p & \text { if she buys a unit of a product of quality } q \text { at price } p \\
0 & \text { otherwise }
\end{array}\right.
$$

Consumers buy at most one unit. We assume the consumer-specific quality taste parameter $\theta$ is uniformly distributed over the set $[0, \bar{\theta}], \bar{\theta}>0$. Preferences of foreign consumers are also given by (1) but we allow for a population of measure $m^{*}\left(m^{*} \geq 1\right)$ to live abroad and for the foreign taste parameter $\theta^{*}$ to be uniformly distributed over the set $\left[0, \lambda^{*} \bar{\theta}\right], \lambda^{*}>1$. Tirole (1988) shows that $\theta$ in (1) is the inverse of the marginal utility of income. As $\theta$ is distributed over the set $[0, \bar{\theta}]$ and $\theta^{*}$ over the set $\left[0, \lambda^{*} \bar{\theta}\right]$, higher incomes are observed in the foreign country if $\lambda^{*}>1$. In our framework, $\lambda^{*}$ is therefore a measure of the difference in incomes across countries. 
We assume there are two firms, one in each country. Let $q$ and $q_{\ell}$ denote the quality produced by the home firm to be sold at home and abroad respectively. Likewise, let $q^{*}$ and $q_{h}^{*}$ denote the quality produced by the foreign firm to be sold locally and abroad respectively. Following Eaton and Schmitt (1994), we introduce production flexibility in this model by assuming that firms first develop one basic product, and then produce variations on these basic products at a lower or no cost. Firms incur fixed costs of quality development; flexibility amounts to assuming cost functions of the form: $C\left(q, q_{\ell}\right)=c \max \left\{q, q_{\ell}\right\}^{2} / 2$ and $C^{*}\left(q^{*}, q_{h}^{*}\right)=c^{*} \max \left\{q^{*}, q_{h}^{*}\right\}^{2} / 2$. As $c$ and $c^{*}$ are expressed in different currencies, let us introduce $e$, the forward exchange rate given to the firms defined as the domestic currency price of foreign currency. ${ }^{1}$ We assume $c>e c^{*}$, that is, the foreign firm is more efficient than the domestic firm in producing any quality level. We normalize the marginal costs of production to zero.

Given these assumptions, Moraga-González and Viaene (2004) show that it is optimal for an individual firm to sell the same level of quality abroad and locally, i.e., $q^{*}=q_{h}^{*}$, and $q=q_{\ell}$. A second useful result is that the foreign firm will manufacture a product of higher quality than the domestic firm's one, i.e., $q_{h}^{*}>q_{\ell}$; this result follows from an application of the risk-dominance selection criterion of Harsany and Selten (1988) and hinges upon the fact that the foreign firm is more efficient than the local firm. ${ }^{2}$

On the basis of these results, in what follows, we shall derive profits functions with two qualities, low quality $q_{\ell}$ and high quality $q_{h}^{*}$. We start by deriving domestic demands for both variants. Define first the corresponding prices charged in the domestic economy by $p$ and $p_{h}^{*}$, respectively, with $p_{h}^{*}>p$. Denote by $\widetilde{\theta}$ the buyer who is indifferent between high quality or low quality. From (1), it follows that $\widetilde{\theta}=\left(p_{h}^{*}-p\right) /\left(q_{h}^{*}-q_{\ell}\right)$. Denote by $\widehat{\theta}$, the consumer indifferent between acquiring low quality or nothing. From (1), we get $\widehat{\theta}=p / q_{l}$. As we have identified two consumers that are indifferent at the margin, we know that the high-quality good is demanded by those consumers such that $\widetilde{\theta} \leq \theta \leq \bar{\theta}$ and the low-quality good by those consumers such that $\widehat{\theta} \leq \theta<\widetilde{\theta}$. Consumers in the interval $0 \leq \theta<\widehat{\theta}$ prefer not to consume. As $\theta$ is uniformly distributed on $[0, \bar{\theta}]$ :

$$
D_{\ell}(.)=\frac{p_{h}^{*}-p}{\bar{\theta}\left(q_{h}^{*}-q_{\ell}\right)}-\frac{p}{\bar{\theta} q_{l}}, D_{h}(.)=1-\frac{p_{h}^{*}-p}{\bar{\theta}\left(q_{h}^{*}-q_{\ell}\right)}
$$

\footnotetext{
${ }^{1}$ The forward exchange rate remains fixed over the time horizon during which product quality is selected.

${ }^{2}$ Motta et al. (1997) also use this criterion to select amongst equilibria in a context where countries differ in the sophistication of demand and firms first operate in autarky and then under free trade. Differences in consumer tastes influence firms' choice of qualities under autarky, which in turn play a selection role when trade opens up. See also Cabrales and Motta (2001).
} 
Note that domestic demand $D_{h}$ of high quality is met by imports from the foreign firm at the price $p_{h}^{*}$. Foreign demands for both variants are obtained in a similar way. First denote $p_{\ell}$ and $p^{*}$ as the price of low quality and of high quality charged in the foreign market, respectively, and recall that the foreign preference parameter $\theta^{*}$ is uniformly distributed on $\left[0, \lambda^{*} \bar{\theta}\right]$, then:

$$
D_{\ell}^{*}=m^{*}\left(\frac{p^{*}-p_{\ell}}{\lambda^{*} \bar{\theta}\left(q_{h}^{*}-q_{\ell}\right)}-\frac{p_{\ell}}{\lambda^{*} \bar{\theta} q_{\ell}}\right), D_{h}^{*}=m^{*}\left(1-\frac{p^{*}-p_{\ell}}{\lambda^{*} \bar{\theta}\left(q_{h}^{*}-q_{\ell}\right)}\right)
$$

Note that foreign demand $D_{\ell}^{*}$ of low quality is met by imports from the domestic firm at the price $p_{\ell}$.

We study a three-stage game. First, the domestic government and the foreign government choose a trade policy to maximize national welfare. The trade policy stage consists of the simultaneous announcement of an ad valorem tariff rate on imports; we denote these tariffs by $t$ and $t^{*}$ respectively. While governments can choose the height of tariff protection, it is assumed that they cannot determine the exchange rate. In the second stage, firms select simultaneously their quality levels and incur the fixed costs of quality development. In the third stage, firms select their prices. We solve the model by backward induction.

\section{Conditions for Dumping}

We now proceed to derive the equilibrium outcome in stage 3 taking $(i)$ any profile of quality choices $\left(q_{\ell}, q_{h}^{*}\right),(i i)$ trade policies $\left(t, t^{*}\right)$ and $(i i i)$ the exchange rate as given. Using the derived domestic demands in (2), foreign demands in (3) and cost functions, the problem of the domestic firm is to select prices $p$ and $p_{\ell}$ so as to maximize profits:

$$
\pi=p D_{\ell}+e p_{\ell}\left(1-t^{*}\right) D_{\ell}^{*}-\frac{c}{2} q_{\ell}^{2}
$$

where $p_{\ell}\left(1-t^{*}\right)$ is the international price of low-quality exports and to convert it into domestic currency we multiply it by the exchange rate $e$. Likewise, the decision problem of the foreign firm is to find $p^{*}$ and $p_{h}^{*}$ so as to maximize the following profit function:

$$
\pi^{*}=p^{*} D_{h}^{*}+\frac{p_{h}^{*}(1-t)}{e} D_{h}-\frac{c^{*}}{2} q_{h}^{* 2}
$$

where $p_{h}^{*}(1-t)$ is the international price of foreign firm's high-quality exports and by dividing by the exchange rate foreign export receipts are converted into foreign currency. Solving the pair of best-response functions in prices, we obtain the subgame equilibrium prices of both variants: 


$$
\begin{gathered}
p=\frac{\bar{\theta} q_{\ell}\left(q_{h}^{*}-q_{\ell}\right)}{\left(4 q_{h}^{*}-q_{\ell}\right)}, p_{\ell}=\frac{\lambda^{*} \bar{\theta} q_{\ell}\left(q_{h}^{*}-q_{\ell}\right)}{\left(4 q_{h}^{*}-q_{\ell}\right)} \\
p^{*}=\frac{2 \lambda^{*} \bar{\theta} q_{h}^{*}\left(q_{h}^{*}-q_{\ell}\right)}{\left(4 q_{h}^{*}-q_{\ell}\right)}, p_{h}^{*}=\frac{2 \bar{\theta} q_{h}^{*}\left(q_{h}^{*}-q_{\ell}\right)}{\left(4 q_{h}^{*}-q_{\ell}\right)}
\end{gathered}
$$

Equilibrium prices depend on qualities and on the primitive parameters $\lambda^{*}$ and $\bar{\theta}$. They are such that $p p^{*}=p_{\ell} p_{h}^{*}$, that is the product of domestic prices is equal to the product of export prices.

We now examine firms' second-stage decisions: the quality selection. In this stage firms take $(i)$ trade policies $\left(t, t^{*}\right)$ and (ii) the exchange rate as given and, anticipating the equilibrium prices of the continuation game obtained in (6) and (7), select the quality of their products. The domestic firm selects $q_{\ell}$ to maximize reduced-form profits:

$$
\pi_{\ell}=\bar{\theta}\left(1+e\left(1-t^{*}\right) \lambda^{*} m^{*}\right) \frac{q_{\ell} q_{h}^{*}\left(q_{h}^{*}-q_{\ell}\right)}{\left(4 q_{h}^{*}-q_{\ell}\right)^{2}}-c \frac{q_{\ell}^{2}}{2}
$$

Likewise, the foreign firm chooses $q_{h}^{*}$ to maximize:

$$
\pi_{h}^{*}=4 \bar{\theta}\left(\frac{(1-t)}{e}+\lambda^{*} m^{*}\right) \frac{\left(q_{h}^{*}\right)^{2}\left(q_{h}^{*}-q_{\ell}\right)}{\left(4 q_{h}^{*}-q_{\ell}\right)^{2}}-c^{*} \frac{\left(q_{h}^{*}\right)^{2}}{2}
$$

Define $\mu$ as the quality gap between firm's product quality, $\mu=q_{h}^{*} / q_{\ell}>1$. The ratio of first-order conditions with respect to qualities can be written as:

$$
\frac{\mu^{2}(4 \mu-7)}{4\left(4 \mu^{2}-3 \mu+2\right)}=\frac{c}{e c^{*}}\left(\frac{(1-t)+e \lambda^{*} m^{*}}{1+e \lambda^{*} m^{*}\left(1-t^{*}\right)}\right)
$$

This equation gives the equilibrium measure of product differentiation $\mu$ as an implicit function of relative costs in same currency units, ad valorem tariffs and the primitive parameters of the model. Since the LHS of (10) is monotonically increasing in $\mu$, and the RHS is a strictly positive number, there exists a unique real solution to this third degree polynomial that can be expressed as follows:

$$
\mu=F\left(\stackrel{+}{c}, c^{*}, \bar{e}, \bar{t}, t^{*}, \lambda^{*}, m^{*}\right)
$$

From 10 it is clear that an equilibrium exists if $\mu>7 / 4$. The signs reported in (11) give the relationship between the equilibrium quality gap $\mu$ and the primitive parameters of the model, as well as countries' tariff rates. For example, if the exchange rate increases, the equilibrium degree of product differentiation falls. 
Knowing $\mu$ and using the reaction functions in qualities, we can derive the market equilibrium of our model (demands, prices and qualities):

$$
\begin{gathered}
D_{\ell}=\frac{\mu}{(4 \mu-1)}, D_{h}=\frac{2 \mu}{(4 \mu-1)} \\
D_{\ell}^{*}=\frac{m^{*} \mu}{(4 \mu-1)}, D_{h}^{*}=\frac{2 m^{*} \mu}{(4 \mu-1)} \\
p=\frac{\bar{\theta} q_{\ell}(\mu-1)}{(4 \mu-1)}, p_{\ell}=\frac{\lambda^{*} \bar{\theta} q_{\ell}(\mu-1)}{(4 \mu-1)} \\
p^{*}=\frac{2 \lambda^{*} \bar{\theta} q_{h}^{*}(\mu-1)}{(4 \mu-1)}, p_{h}^{*}=\frac{2 \bar{\theta} q_{h}^{*}(\mu-1)}{(4 \mu-1)} \\
q_{\ell}=\frac{\bar{\theta}\left(1+e\left(1-t^{*}\right) \lambda^{*}\right)}{c} \frac{\mu^{2}(4 \mu-7)}{(4 \mu-1)^{3}} \\
q_{h}^{*}=\frac{4 \bar{\theta}\left(\lambda^{*} m^{*}+(1-t) / e\right)}{c^{*}} \frac{\mu\left(4 \mu^{2}-3 \mu+2\right)}{(4 \mu-1)^{3}}
\end{gathered}
$$

A first characteristic of the market equilibrium is that the quality gap $\mu$ is also measure of price competition in the domestic and foreign market. Taking the ratio of prices:

$$
\frac{p_{h}^{*}}{p}=2 \mu, \frac{p^{*}}{p_{\ell}}=2 \mu
$$

An increase in product differentiation decreases therefore price competition in both markets. The reason for this outcome is that in the presence of international trade firms consider the world as a single market and choose their quality to maximize global profits. Second, the equilibrium exhibits intra-industry trade in vertically differentiated goods. The quantities $D_{\ell}^{*}$ and $D_{h}$ represent domestic exports of low-quality products and domestic imports of the high-quality variant, respectively. The corresponding Grubel-Lloyd (GL) index in value is:

$$
G L=100\left\{1-\frac{\left|p_{\ell} D_{\ell}^{*}-p_{h}^{*} D_{h}\right|}{p_{\ell} D_{\ell}^{*}+p_{h}^{*} D_{h}}\right\}=100\left\{1-\frac{\left|\lambda^{*} m^{*}-4 \mu\right|}{\lambda^{*} m^{*}+4 \mu}\right\}
$$

When measured at international prices, the GL index in values depends on $\lambda^{*}, m^{*}$ and, via $\mu$, on the rest of parameters of the model.

The determination of dumping relies on three principles. First, domestic and export goods must be "like" products. The term "like" product means alike in all respects or having characteristics 
closely resembling those of the product under consideration. In practise, though quality differentiation is discussed in investigations, it hardly leads to a classification of low-quality and high-quality goods in different industries. Second, a local firm may petition the government for relief if dumped imports materially injure the competing domestic firm. In the market equilibrium just obtained, domestic and foreign demands are such that the foreign firm's market share is two thirds of the domestic market and the domestic firm's share in the foreign market is one third. It is clear that both proportions are large enough to justify injury. Third, a product is to be considered as being dumped if its export price to a particular country is less than a "normal value."

The WTO provides two main methods to calculate a product's "normal value." The first one is a calculation based on the combination of the exporter's production costs and normal profit margins. The second, and most frequently used, method is based on the price in the exporter's domestic market (see the WTO website). These two definitions of dumping are implemented in turn, each leading to a different proposition. ${ }^{3}$

Proposition 1 When "normal value" is based on total average costs, then: (i) there is no dumping by the low-quality firm (for realistic values of $t^{*}$ ); (ii) the high-quality firm dumps in the developing economy if

$$
\frac{2\left(1+m^{*}\right)}{1+e \lambda^{*} m^{*} /(1-t)}<\frac{4 \mu^{2}-3 \mu+2}{4 \mu^{2}-5 \mu+1}
$$

where $\mu$ is the solution to (10).

Proof. ( $i$ ) There is dumping by the domestic firm abroad if $p_{l}\left(1-t^{*}\right) e<c q_{l}^{2} /\left(2\left(D_{l}+D_{l}^{*}\right)\right)$. Substituting the expressions obtained in the market equilibrium, this is the case if

$$
\frac{2 e\left(1-t^{*}\right) \lambda^{*}\left(1+m^{*}\right)}{1+e\left(1-t^{*}\right) \lambda^{*}}<\frac{4 \mu^{2}-7 \mu}{4 \mu^{2}-5 \mu+1}
$$

which cannot hold for two reasons. First, the RHS of (15) is less than 1. Second, the LHS of (15) is greater than 1 as long as $\left(1-1 /\left(e \lambda^{*}\left(1+2 m^{*}\right)\right)>t^{*}\right.$; since $\lambda^{*}$ and $m^{*}$ are greater than 1 and, typically, $e$ is large and $t^{*}$ small, this inequality holds. ( $\left.i i\right)$ There is dumping by the foreign firm in the domestic economy if $p_{h}^{*}(1-t) / e<c^{*} q_{h}^{* 2} /\left(2\left(D_{h}^{*}+D_{h}\right)\right)$. After substitution, one obtains condition (14).

The high-quality firm derives its profits from its own market but tries to recoup part of the development costs by exporting. As the export market is poorer, a low export price is charged.

\footnotetext{
${ }^{3}$ The theoretical literature has also used the competing local price of imports as a proxy for the normal value (Vandenbussche and Wauthy, 2001). In terms of our model, such a comparison is done in terms of hedonic prices as it concerns goods of different qualities. The result is that only dumping by the low-quality firm is observed.
} 
Another observation has to do with the presence of the home tariff rate in (14). Dumping is believed to be intimately related to the existence of international tariff policies. As we have seen already, an important characteristic of developing and transition economies is the high levels of duties imposed on imports. It is argued that high import tariffs have the perverse effect of forcing a foreign company to dump in order to enter a market, subjecting itself to anti-dumping actions. This view has been repeatedly put forward by various international organizations and governments (see for example, EC (2003)). Condition (14) examines the theoretical premises of such conjecture. It is clear that the tariff rate is instrumental in determining the likelihood of dumping by the foreign firm into the domestic market: an increase in $t$ decreases the LHS of (14) and, since the RHS of (14) is decreasing in $\mu$, it increases the RHS of (14).

We now turn to the standard definition of dumping: when the export price to a particular country is less than the price the firm normally charges on its own market. Then:

Proposition 2 Under the WTO standard, (i) dumping by the foreign firm in the domestic market occurs if $\lambda^{*}>(1-t) / e$; (ii) dumping by the domestic firm abroad takes place if $\lambda^{*}<1 /\left(1-t^{*}\right) e$; (iii) reciprocal dumping arises if

$$
\frac{1-t}{e}<\lambda^{*}<\frac{1}{\left(1-t^{*}\right) e}
$$

As a result, unilateral dumping always occurs, while reciprocal dumping can only arise if tariff rates are strictly positive.

Proof. ( $i$ ) This is the case if the international foreign currency price of high-quality exports is less than the local price, i.e. $p_{h}^{*}(1-t) / e<p^{*}$. Using (7), this implies $(1-t) / e<\lambda^{*}$. (ii) This is the case if $e p_{\ell}\left(1-t^{*}\right)<p$, which using (6) implies $\lambda^{*}<1 /\left(1-t^{*}\right) e$. (iii) This result follows from combining the previous two inequalities.

Proposition 2 leads to a number of observations:

- First, dumping is a natural price strategy of firms because it always takes place (irrespective of whether domestic tariffs are zero or positive).

- Second, traditional treatments of dumping have obtained conditions for reciprocal dumping based on transportation costs in an international duopoly (Brander and Krugman, 1983) and conditions for unilateral and reciprocal dumping based on transportation costs in an international oligopoly (Weinstein, 1992). Differently, condition (16) demonstrates that unilateral or 
reciprocal dumping arises when the cross-country difference in incomes falls within or outside an interval created by the exchange rate and the domestic and foreign tariff rates.

The role of exchange rate changes on the extent of dumping is clarified in the following corollary of Proposition 2:

Corollary. A depreciation of the domestic currency (increase in e) increases the likelihood of dumping by the foreign firm in the domestic market and decreases the likelihood of dumping by the domestic firm abroad.

This result follows directly from (16) and emphasizes the fact that exchange rate movements affect firms in opposite directions. Ceteris paribus, an increase in the exchange rate $e$ increases the gap between the international foreign currency price of high-quality and the local price abroad while it decreases the difference between the domestic currency price of low-quality exports and the domestic price. ${ }^{4}$

\section{Trade Policies}

In the first stage of the game each government chooses a tariff rate to maximize social welfare. As mentioned above, solutions for $t$ and $t^{*}$ are useful in determining whether unilateral or reciprocal dumping can arise in equilibrium. Also, if it is unilateral, which of the two firms is likely to dump its products.

In each country, social welfare $(W)$ equals the unweighted sum of domestic consumer surplus $(C S)$, domestic firm's profits $(\pi)$ and tariff revenues $(R)$. In the domestic country, consumer surplus is given by:

$$
C S=\int_{\tilde{\theta}}^{\bar{\theta}}\left(\theta q_{h}-p_{h}\right) d F(\theta)+\int_{\hat{\theta}}^{\tilde{\theta}}\left(\theta q_{\ell}-p_{\ell}\right) d F(\theta)
$$

Using equilibrium prices of the domestic country, consumer surplus can be rewritten more conveniently as follows:

$$
C S=\frac{\bar{\theta} \mu^{2}(4 \mu+5)}{2(4 \mu-1)^{2}} q_{\ell}
$$

The profits of the domestic firm are:

$$
\pi=\bar{\theta}\left[\frac{1+e\left(1-t^{*}\right) \lambda^{*} m^{*}}{2}\right] \frac{\left(4 \mu^{3}-3 \mu^{2}+2 \mu\right)}{(4 \mu-1)^{3}} q_{\ell}
$$

\footnotetext{
${ }^{4}$ It is important to note that the corollary deals with the effects of exchange rate changes on the likelihood of dumping. This differs from the empirical literature which focus on econometric estimates of exchange rate changes on the number of anti-dumping filings (see e.g. Feinberg, 1989; Knetter and Prusa, 2003).
} 
Finally, tariff revenues accruing from high-quality imports to the domestic country are:

$$
R=t p_{h}^{*} D_{h}=4 \bar{\theta} t \frac{\mu^{2}(\mu-1)}{(4 \mu-1)^{2}} q_{\ell}
$$

Adding these three expressions we obtain the reduced-form expression for domestic social welfare:

$$
W=q_{\ell} \cdot A\left(t, t^{*}, \lambda^{*}, m^{*}, \bar{\theta}, \mu(\cdot)\right)
$$

where $A($.$) collects terms (other than q_{\ell}$ ) of the components of social welfare:

$$
A\left(t, t^{*}, \lambda^{*}, m^{*}, \bar{\theta}, \mu(\cdot)\right)=\frac{\bar{\theta} \mu^{2}(4 \mu+5)}{2(4 \mu-1)^{2}}+\frac{\bar{\theta}\left(1+e\left(1-t^{*}\right) \lambda^{*} m^{*}\right)}{2} \frac{\left(4 \mu^{3}-3 \mu^{2}+2 \mu\right)}{(4 \mu-1)^{3}}+\frac{4 \bar{\theta} t \mu^{2}(\mu-1)}{(4 \mu-1)^{2}} .
$$

An expression for foreign social welfare can be obtained following the same steps:

$$
W^{*}=q_{\ell} \cdot A^{*}\left(t, t^{*}, \lambda^{*}, m^{*}, \bar{\theta}, \mu(\cdot)\right)
$$

Though both welfare levels are proportional to $q_{\ell}$, the factors of proportionality are different and such that $A^{*}(\cdot)>A(\cdot)$ under free trade $\left(t=t^{*}=0\right)$. The main reason is that foreign profits derived from high-quality production are much higher than those the domestic firm derives from low-quality production: $e \pi^{*} / \pi=16 c / e c^{*}$. Note that domestic welfare $W$ is affected by $t$ in two ways. First, it enters directly into the expression for $A(\cdot)$ because of its rent-extracting effect of foreign firm's profits; second it indirectly affects competitive conditions at home and abroad through $\mu$ (see (11)). Similarly, $t^{*}$ captures rents from the domestic firm and alters the competitiveness of the international market.

Let us denote the right hand side of (10) as the relative development cost $r$ and consider the following elasticities $\alpha=(\partial W / \partial \mu)(\mu / W)>0, \beta=(\partial \mu / \partial r)(r / \mu)>0$ and $\gamma=(\partial A / \partial t)(t / A)>0$; also $\alpha^{*}=\left(\partial W^{*} / \partial \mu\right)\left(\mu / W^{*}\right)>0$ and $\gamma^{*}=\left(\partial A^{*} / \partial t^{*}\right)\left(t^{*} / A^{*}\right)>0$. Then, in an interior equilibrium the tariff rates $t$ and $t^{*}$ must satisfy the following first order conditions:

$$
\begin{aligned}
\frac{\gamma}{t}+\frac{\alpha \beta}{1-t+e \lambda^{*} m^{*}} & =0 \\
\frac{\gamma^{*}}{t^{*}}+\alpha^{*} \beta \frac{e \lambda^{*} m^{*}}{1+e \lambda^{*} m^{*}\left(1-t^{*}\right)} & =0
\end{aligned}
$$

This leads the following result.

Proposition 3 In an interior subgame perfect equilibrium (i) the domestic trade policy is such that

$$
t=\frac{\gamma\left(1+e \lambda^{*} m^{*}\right)}{\gamma+\alpha \beta}>0
$$


and the foreign trade policy is characterized by

$$
t^{*}=\frac{-\gamma^{*}\left(1+e \lambda^{*} m^{*}\right)}{e \lambda^{*} m^{*}\left(\alpha^{*} \beta-\gamma^{*}\right)} \gtrless 0
$$

(ii) Moreover $t>t^{*}$ if and only if $\alpha^{*} \beta>\gamma^{*}$.

Part $(i)$ indicates that while it is optimal for the domestic government to levy a tariff, the foreign policymaker may subsidize low-quality imports. Intuitively, when the value of high-quality imports is large, it pays the domestic government to extract positive rents. In contrast, the value of low-quality imports being small, the rent extraction effect of a foreign tariff is small and the foreign government may find it optimal to subsidize imports to reduce the quality gap $\mu$ and increase competition in its local market. Regarding condition (16), setting $t^{*}<0$ or $t^{*}=0$ excludes reciprocal dumping and allows for dumping by the foreign firm in the domestic market only. Part (ii) of the proposition gives some explanation for the observed difference in tariff rates between developed and developing economies.

An interior subgame perfect equilibrium is given by the simultaneous solution to (10), (23) and (24). For example when countries' size and income differences as well as firms' cost asymmetries are negligible, the numerical solution to this system of equations reveals that the equilibrium tariff $t^{*}$ imposed by the foreign government is positive but very close to zero, while the equilibrium tariff $t$ levied by the domestic government is about $64 \%$. The simulations show that as asymmetries between the countries increase, $t$ increases while $t^{*}$ decreases.

\section{Arbitrage and dumping}

So far we have assumed that consumers cannot arbitrage. This is a reasonable assumption in settings where transaction costs associated to the reselling of goods are of sufficient magnitude to render parallel trade unprofitable. In this section we examine whether our conditions for dumping are affected by goods arbitrage. Our first result establishes a condition under which no gain from arbitrage is obtained.

Proposition 4 There is no incentive for the arbitrage of goods via parallel trade if

$$
\frac{1-t}{e}<\lambda^{*}<\frac{1}{\left(1-t^{*}\right) e}
$$

Proof. Resale of high-quality goods from the domestic country to the foreign country is not profitable if $p_{h}^{*}>e\left(1-t^{*}\right) p^{*}$. Using $(7)$, this implies $\lambda^{*}<1 /\left(1-t^{*}\right) e$. This condition also guarantees 
that consumers at home do not gain by buying low-quality goods from the home firm and exporting them in turn to the foreign country. Re-shipment of low-quality goods from the foreign to the domestic country does not occur if $p_{l}>p(1-t) / e$. Using $(7)$, this implies $\lambda^{*}>(1-t) / e$. This condition also ensures that foreign consumers do not benefit from parallel exporting high quality.

The condition for unprofitable arbitrage possibilities in (25) is similar to that for reciprocal dumping in (16). As a result, pricing policies of firms are such that when reciprocal dumping occurs no incentive for parallel trading exists.

According to Proposition 4, arbitrage possibilities arise if condition (25) is not fulfilled. Since this condition can only be violated in one direction, two-way arbitrage is generally excluded, except for specific values of $t$ and $t^{*}$, in particular satisfying $(1-t)\left(1-t^{*}\right)=1$. Since one-way arbitrage is possible, the question is whether dumping can still be observed when consumers exhaust all arbitrage possibilities. The next result indicates that it depends on the height of import tariffs in both countries.

Proposition 5 (a) Let $\lambda^{*} \geq 1 /\left(1-t^{*}\right)$ e. Then if $(1-t)\left(1-t^{*}\right)<1$ dumping by the foreign firm arises even if consumers exhaust all arbitrage possibilities for high-quality goods. Otherwise, if $(1-t)\left(1-t^{*}\right) \geq 1$, arbitrage prevents dumping by the foreign firm. (b) Let $\lambda^{*} \leq 1 /\left(1-t^{*}\right)$ e. Then if $(1-t)\left(1-t^{*}\right)<1$ dumping by the domestic firm arises even if consumers exhaust all arbitrage possibilities for low-quality goods. Otherwise, if $(1-t)\left(1-t^{*}\right) \geq 1$, arbitrage prevents dumping by the domestic firm.

Proof. (a) Suppose $\lambda^{*} \geq 1 /\left(1-t^{*}\right) e$. Since $\lambda^{*}=p_{\ell} / p=p^{*} / p_{h}^{*}$, domestic consumers gain from reselling low-quality and high-quality goods. If consumers exhaust all arbitrage possibilities, it must be the case that $p_{h}^{*}=e\left(1-t^{*}\right) p^{*}$ and that $p=e\left(1-t^{*}\right) p_{\ell}$. Or $\lambda^{*}=1 /\left(1-t^{*}\right) e$. Dumping of high quality goods arises if $p_{h}^{*}(1-t) / e<p^{*}$, or if $\lambda^{*}>(1-t) / e$. Combining the two conditions on $\lambda^{*}$ yields the result. (b) The proof is similar and, to save space, omitted.

\section{Conclusion}

This paper has investigated the question why developing and transition economies have increasingly enacted anti-dumping laws in the last few years. We have found that governments in transition and developing economies have strong incentives to levy tariffs on high-quality imports because 
of its substantial rent-extracting effects. This trade policy has, however, two additional effects. First, it affects the pricing behavior of exporting firms and increases the likelihood of unilateral and reciprocal dumping. Second, it renders the arbitrage of goods, through parallel trade and the re-shipment of exports, ineffective in the sense that it does not prevent dumping by the foreign firm. These two observations explain why these countries have enacted anti-dumping laws to counteract the effects of their trade policies. The next step is to analyze anti-dumping policy. Hopefully the analysis above offers a useful framework within which the analysis of anti-dumping instruments can be conducted. 


\section{Appendix: Glossary of Symbols}

$c, c^{*} \quad$ domestic, foreign quality development cost (in own currency)

$C S \quad$ domestic consumer surplus

$D_{\ell}, D_{\ell}^{*} \quad$ domestic, foreign demand for low quality

$D_{h}, D_{h}^{*} \quad$ domestic, foreign demand for high quality

$e \quad$ forward exchange rate (domestic price of foreign currency)

GL Grubel-Lloyd index

$m^{*} \quad$ population size abroad $\left(m^{*} \geq 1\right)$

$p \quad$ domestic currency price of low-quality consumption

$p^{*} \quad$ foreign currency price of high-quality consumption

$p_{\ell} \quad$ foreign currency price of low-quality exports

$p_{h}^{*} \quad$ domestic currency price of high-quality exports

$q_{\ell} \quad$ low quality (produced at home only)

$q_{h}^{*} \quad$ high quality (produced abroad only)

$r \quad$ relative development cost

$R \quad$ domestic tariff revenues

$t \quad$ domestic ad valorem tariff rate $(t \gtrless 0)$

$t^{*} \quad$ foreign ad valorem tariff rate $\left(t^{*} \gtrless 0\right)$

$W \quad$ domestic social welfare

$W^{*} \quad$ foreign social welfare

$\theta, \theta^{*} \quad$ domestic, foreign taste parameter

$\bar{\theta} \quad$ highest taste parameter observed at home

$\widehat{\theta} \quad$ consumer indifferent between low quality or no purchase

$\widetilde{\theta} \quad$ consumer indifferent between high and low quality

$\lambda^{*} \quad$ relative taste parameter $(\lambda>1)$

$\mu \quad$ quality gap $\left(q_{h}^{*} / q_{\ell}\right)$ 


\section{References}

[1] Aturupane, C., S. Djankov and B. Hoekman (1999), "Horizontal and Vertical Intra-Industry Trade between Eastern Europe and the European Union," Weltwirtschaftliches Archiv 135(1), $62-81$.

[2] Blonigen, B.A. and T.J. Prusa (2003), "Antidumping", in E.K. Choi and J. Harrigan (Eds.), Handbook of International Trade (Oxford, UK and Cambridge, MA: Blackwell Publishers), Chapter 9 .

[3] Brander, J.A. and P.R. Krugman (1983), "A 'Reciprocal Dumping' Model in International Trade," Journal of International Economics 15, 313-323.

[4] Cabrales, A. and M. Motta (2001), "Country Asymmetries, Endogenous Product Choice and the Timing of Trade Liberalization," European Economic Review 45, 87-107.

[5] Eaton, B.C. and N. Schmitt (1994), "Flexible Manufacturing and Market Structure," American Economic Review, 84(4), 875-888.

[6] European Community-EC (2002), Submission from the European Communities Concerning the Agreement on Implementation of Article VI of GATT 1994, WTO Doha Development Agenda Negotiations, Brussels.

[7] European Community-EC (2003), Twentieth Annual Report from the Commission to the European Parliament on the Community's Anti-Dumping and Anti-Subsidy and Safeguard Activities, Brussels (http://europa.eu.int/comm/trade/policy/dumping/reports.htm).

[8] Feinberg, R. M. (1989), "Exchange Rates and Unfair Trade," Review of Economics and Statistics 71, 704-707.

[9] Finger, J.M., F. Ng and S. Wangchuk (2000), "Antidumping as Safeguard Policy," Manuscript, World Bank, Washington DC.

[10] Greenaway, D., R. Hine, and C. Milner (1994), "Country Specific Factors and the Pattern of Horizontal and Vertical Intra-Industry Trade in the U.K.," Weltwirtschaftsliches Archiv 131, 77-100.

[11] Greenaway, D., R. Hine, and C. Milner (1995), "Horizontal and Vertical Intra-Industry Trade: A Cross Industry Analysis for the UK, "Economic Journal 105, 1505-1518. 
[12] Harsanyi, J. C. and R. Selten (1988), A General Theory of Equilibrium in Games, Cambridge, MA: MIT Press.

[13] Knetter, M. M. and T. J. Prusa (2003), "Macroeconomic Factors and Antidumping Filings: Evidence from Four Countries," Journal of International Economics 61(1), 1-17.

[14] Lankhuizen, M. (2000), "Shifts in Foreign Trade, Competitiveness and Growth Potential: from Baltics to 'Bal-Techs'?," Research Policy 29, 9-29.

[15] Moraga-González, J.L. and J.-M. Viaene (2004), "Anti-Dumping, Intra-Industry Trade and Quality Reversals", Tinbergen Institute Discussion paper. (downloadable from http://www.tinbergen.nl/ ${ }^{\sim}$ moraga/reversals.pdf)

[16] Motta, M., J.-F. Thisse and A. Cabrales (1997), "On the Persistence of Leadership or Leapfrogging in International Trade," International Economic Review 38(4), 809-824.

[17] Tirole, J. (1988), The Theory of Industrial Organization, Cambridge, MA: MIT Press.

[18] United States International Trade Commission - USITC (2001), "Canned Pineapple Fruit from Thailand," USITC Publication No. 3417, Washington DC.

[19] United States International Trade Commission - USITC (2002), "Certain Folding Metal Tables and Chairs from China," USITC Publication No. 3515, Washington DC.

[20] Vandenbussche, H. and X. Wauthy (2001), "Inflicting Injury through Product Quality: How EU Anti-dumping Policy Disadvantages European Producers," European Journal of Political Economy 17, 101-116.

[21] Weinstein, D.E. (1992), "Competition and Unilateral Dumping," Journal of International Economics 32, 379-387. 